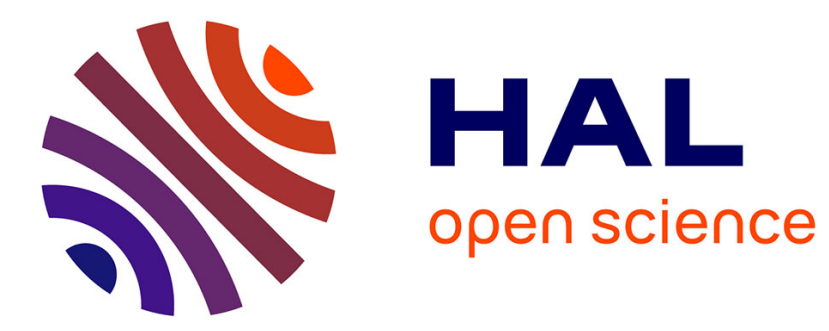

\title{
Wetting of fibers : theory and experiments
}

David Quéré, Jean-Marc Di Meglio, Françoise Brochard-Wyart

\section{To cite this version:}

David Quéré, Jean-Marc Di Meglio, Françoise Brochard-Wyart. Wetting of fibers: theory and experiments. Revue de Physique Appliquée, 1988, 23 (6), pp.1023-1030. 10.1051/rphysap:019880023060102300 . jpa-00245903

\section{HAL Id: jpa-00245903 https://hal.science/jpa-00245903}

Submitted on 1 Jan 1988

HAL is a multi-disciplinary open access archive for the deposit and dissemination of scientific research documents, whether they are published or not. The documents may come from teaching and research institutions in France or abroad, or from public or private research centers.
L'archive ouverte pluridisciplinaire HAL, est destinée au dépôt et à la diffusion de documents scientifiques de niveau recherche, publiés ou non, émanant des établissements d'enseignement et de recherche français ou étrangers, des laboratoires publics ou privés. 
Classification

Physics Abstracts

$68.40-68.45$

\title{
Wetting of fibers : theory and experiments
}

\author{
David Quéré $\left({ }^{1,2}\right)$, Jean-Marc Di Meglio $\left({ }^{1}\right)$ and Françoise Brochard-Wyart $\left({ }^{1,3}\right)$ \\ $\left({ }^{1}\right)$ Laboratoire de Physique de la Matière Condensée, UA 792 du C.N.R.S., Collège de France, 11 place \\ Marcelin-Berthelot, 75231 Paris Cedex 05, France \\ ( $\left.{ }^{2}\right)$ ATOCHEM, Centre d'Applications de Levallois, 95 rue Danton, 92203 Levallois-Perret Cedex, France \\ $\left({ }^{3}\right)$ Laboratoire de Structure et Réactivité aux Interfaces, Université Pierre-et-Marie-Curie, 4 place Jussieu, \\ 75231 Paris Cedex 05, France
}

(Reçu le 26 octobre 1987, révisé le 18 janvier 1988, accepté le 8 mars 1988)

Résumé. - Nous rappelons d'abord les résultats théoriques d'un des auteurs (F. B.-W.) sur la statique du mouillage des fibres. Lorsqu'on considère les interactions à longue portée de type Van der Waals entre le solide et le liquide, on montre que la fibre peut être mouillée si le paramètre d'étalement $S$ est supérieur à une valeur seuil $S_{\mathrm{c}}\left(S_{\mathrm{c}}=3 / 2 \gamma(a / b)^{2 / 3}\right.$ avec $\gamma$ la tension de surface du liquide, $b$ le rayon de la fibre et $a=(A / 6 \pi \gamma)^{1 / 2}$ où $A$ est une constante de Hamaker $\left.\left(A=A_{\mathrm{SL}}-A_{\mathrm{LL}}\right)\right)$. Au-delà de ce seuil, l'épaisseur du film mouillant en contact avec une goutte réservoir est $e_{\mathrm{c}}=a^{2 / 3} b^{1 / 3}$ (c'est l'épaisseur au seuil). Si la fibre est tendue verticalement du réservoir, la situation de mouillage final est donnée par l'équilibre de la pression de disjonction avec les pressions de Laplace et gravitationnelle, c'est-à-dire $e(h) \sim\left(h+\frac{K^{-2}}{b}\right)^{1 / 3}$. Nous présentons ensuite des prédictions théoriques récentes sur la dynamique de ce processus : comme dans le cas de la montée d'un film liquide microscopique le long d'un mur vertical, il convient de distinguer deux régimes : une langue dynamique $\left(e \sim t / h^{2}\right)$ est d'abord émise du ménisque. Elle progresse selon un comportement diffusif, tout comme le film statique qui vient la remplacer. Après un temps caractéristique, il faut tenir compte de la gravité et la progression du film statique obéit à une loi $h \sim t^{3 / 5}$. Il rattrape donc le film dynamique à la hauteur finale d'équilibre $\bar{H}$. Ces prédictions théoriques sont confrontées avec une expérience originale de mouillage de fibres verticales par une solution marquée en spin, les films étant détectés par RPE. La vitesse avec laquelle le film monte est anormalement grande, ce que nous avons montré être dû à des rayures axiales de la fibre. Nous pensons néanmoins que les interactions de Van der Waals contrôlent l'état final du film liquide : le profil $e(h)$ qui s'établit est compatible avec la théorie.

Abstract. - We first present a digest of a previous theoretical study of one of us (F. B.) about the static aspects of wetting of thin fibers. This study includes the effects of long range Van der Waals interactions. Two points merit special attention : (i) the threshold value $S_{\mathrm{c}}$ of the spreading parameter for complete wetting is greater than zero $\left(S_{\mathrm{c}}=3 / 2 \gamma(a / b)^{2 / 3}\right.$ with $\gamma$ the liquid surface tension, $b$ the fiber radius and $a=(A / 6 \pi \gamma)^{1 / 2}$ where $A$ is a Hamaker constant $\left.\left(A=A_{\mathrm{SL}}-A_{\mathrm{LL}}\right)\right)$; and (ii) when $S>S_{\mathrm{c}}$ and when the liquid is in contact with a reservoir of zero-curvature, the thickness of this wetting film is locked to $e_{\mathrm{c}}=a^{2 / 3} b^{1 / 3}$, i.e. the thickness for $S=S_{\text {c. }}$. A recent study about the dynamics of such a microscopic film is then presented : the situation of upward creeping of a liquid on a fiber is specially studied. As for the planar geometry two regimes can be distinguished : a static regime, defined by the equilibrium between disjoining pressure, Laplace pressure and gravity: $e(h) \sim\left(h+\frac{K^{-2}}{b}\right)^{-1 / 3}$ and a dynamic regime where viscous terms have to be considered while gravity can be neglected : $e(h, t) \sim t / h^{2}$. These two profiles first creep with diffusion equations. After a characteristic time, the static profile then follows a $h_{\mathrm{S}} \sim t^{3 / 5}-$ law and catches the diffusive tongue up at the final equilibrium height $\bar{H}$. These theoretical predictions are tested by a new set of experiments using spin labels and electron spin resonance (ESR). Not all our results are understood via our theory. Particularly the creeping velocity is too large when compared to theory. The explanation of this discrepancy is due to surface roughness. Nevertheless we believe that Van der Waals interactions are relevant in our problem : the final state seems to involve a static wetting film along the fiber. 


\section{Introduction.}

The understanding of wetting of thin fibers (diameter less than $100 \mu \mathrm{m}$ ) is crucial in many industrial fields : composite materials [1] (like carbon-reenforced resins), textiles (spinning and dyeing), paper industry and other growing areas.

Wetting of fibers is peculiar especially when compared to the planar geometry [2] because of the additional radius of curvature. Let us imagine a fiber covered by a liquid film (Fig. 1b) : the outer free surface of the liquid does not match the solid-liquid contact surface. Thus a non-zero Laplace pressure exists inside the film and will increase with the spreading of the liquid. These physical evidences will show up in both statics and dynamics of fiber wetting. We recall in this paper recent theoretical studies about statics [3] and dynamics [4] and we present new experimental results.

\section{Statics.}

2.1 CRITICAL SPREADING PARAMETER AND THICKNESS OF THE WETTING FILM. - Let us consider the two following situations :

- a large unspreaded liquid drop of radius $R$ on a fiber of radius $b$ (Fig. 1a);

- the same fiber covered with a uniform liquid film of thickness $e$ (Fig. 1b).

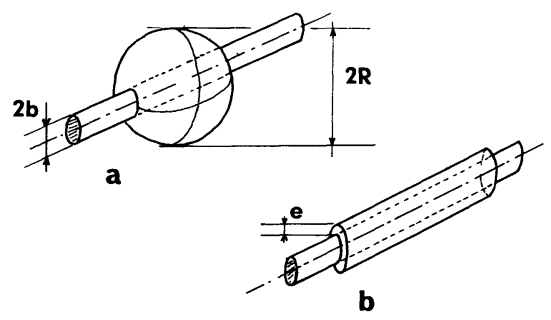

Fig. 1. - (a) unspreaded drop $(R \gg b)$; (b) liquid covered fiber $(e \ll b)$.

The free energy per unit volume of the former is :

$$
f_{1}=\frac{4 \pi R^{2} \gamma}{\frac{4}{3} \pi R^{3}} \quad(R \gg b)
$$

with $\gamma$ the surface tension of the liquid, while for the latter we get :

$$
f_{2}=\frac{-2 b S+2 \gamma e+2 P(e) b}{e(2 b+e)}
$$

the first term of (2) represents the interfacial energy - $S \mathcal{A}, S$ being the spreading parameter : $S=\gamma_{\mathrm{SV}}-$ $\gamma_{\mathrm{SL}}-\gamma$ and $A$ the wetted area. The second term is associated with the excess interfacial energy due to the curvature of the film and the last term is the long-range interaction term. For non-retarded Van der Waals interactions, with $A_{\mathrm{SL}}$ and $A_{\mathrm{LL}}$ being respectively the Hamaker constants for solid-liquid and liquid-liquid interactions $P(e)=\frac{A_{\mathrm{SL}}-A_{\mathrm{LL}}}{12 \pi e^{2}}$ (we set $\gamma a^{2}=\frac{A_{\mathrm{SL}}-A_{\mathrm{LL}}}{6 \pi}$, typically $a=3 \AA$ ). By comparing $f_{1}$ and $f_{2}$, we can determine the most stable state.

The film will be stable if $f_{2}-f_{1}<0$ and $\frac{\partial\left(f_{2}-f_{1}\right)}{\partial e}=0$. The transition between the two states occurs when :

$$
\begin{aligned}
& S_{\mathrm{c}}=e_{\mathrm{c}} \pi\left(e_{\mathrm{c}}\right)+P\left(e_{\mathrm{c}}\right) \\
& \pi\left(e_{\mathrm{c}}\right)=\gamma / b
\end{aligned}
$$

$\pi(e)$ is the disjoining pressure $\pi(e)=-\frac{\mathrm{d} P}{\mathrm{~d} e}$. This gives :

$$
\left\{\begin{array}{l}
S_{\mathrm{c}}=\frac{3}{2} \gamma \frac{e_{\mathrm{c}}}{b} \\
e_{\mathrm{c}}^{3}=a^{2} b
\end{array}\right.
$$

for $S<S_{\mathrm{c}}$, the unspreaded drop state is favored [5] ; for $S=S_{\mathrm{c}}$, a wetting film of thickness $e_{\mathrm{c}}$ develops; for $S>S_{\mathrm{c}}$, this wetting film has a thickness equal to :

$$
e_{0}=a\left(\frac{3 \gamma}{2 S}\right)^{1 / 2}
$$

like for the planar case [2]. We should note that it is theoretically possible to imagine a situation where $0<S<S_{\mathrm{c}}$, i.e. the liquid would wet a planar surface but would not wet a fiber made of the same material. For a fiber of length $L$, the optimum volume of liquid is $2 \pi b e_{0} L$ with $e_{0}$ given by (4). With a larger volume of liquid put on the fiber, it can be easily shown that the final state is a large reservoir drop in equilibrium with a wetting film of thickness $e_{\mathrm{c}}$, $e_{\mathrm{c}}$ given by (3).

\subsection{EQUILIBRIUM PROFILE OF A LIQUID ASCENDING} ON A VERTICAL FIBER (UPWARD CREEPING). - The physical situation is a vertical fiber partially dipped in a large liquid reservoir (Fig. 2a). The film thickness $e(h)$ is a function of the height $h$ above the flat surface. The free energy is :

$$
\begin{aligned}
f= & 2 \pi \int \mathrm{d} h\left[\gamma \sqrt{1+\left(\frac{\mathrm{d} e}{\mathrm{~d} h}\right)^{2}} \times\right. \\
& \times(b+e)+b\left(\gamma_{\mathrm{SL}}-\gamma_{\mathrm{SV}}\right)+ \\
& +P(e) b+\rho g h e(b+e / 2)] .
\end{aligned}
$$

The first two terms are associated with interfacial energies, the third one represents long-range interaction while the last one pictures gravity.

2.2.1 Macroscopic regime: meniscus. - At the bottom of the fiber, where a macroscopic meniscus 


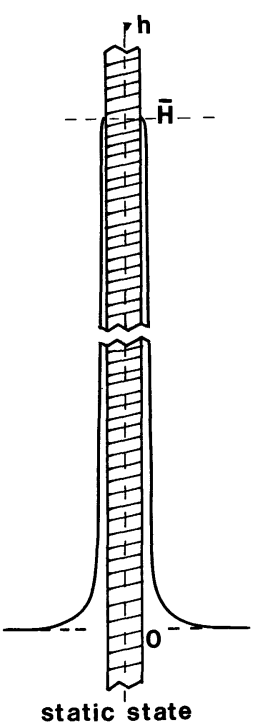

a

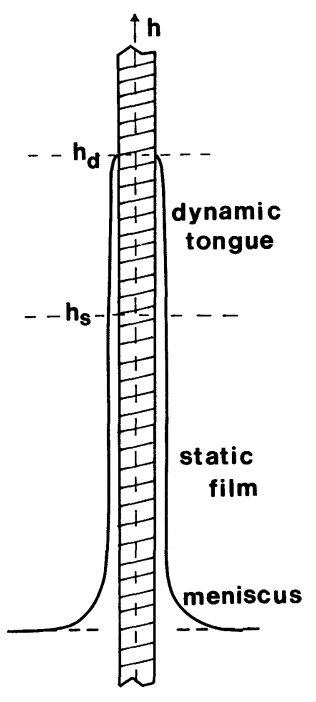

b
Fig. 2. - (a) equilibrium profile ; (b) liquid profile during an upward creep.

stands, we can neglect the long-range interaction term. Minimization of (5) by means of Euler-Lagrange equation yields a catenary profile for $e(h)$ associated with a zero curvature :

$$
e(h)=\ell \cosh \left(\frac{h_{0}-h}{\ell}\right)-b
$$

where $\ell=b\left(\frac{S}{\gamma}+1\right)$ and $h_{0}$ is the height of the edge of the meniscus for $S=0$. When $S>0$, $e$ tends towards $\frac{S}{\gamma} b$ for $h=h_{0}$, while when $S<0$ the meniscus ends up at height $h_{\mathrm{m}}$ given by :

$$
\cos \theta_{\mathrm{e}} \cosh \left(\frac{h_{0}-h_{\mathrm{m}}}{b \cos \theta_{\mathrm{e}}}\right)=1
$$

where $\theta_{\mathrm{e}}$ is the Young contact angle.

2.2.2 Microscopic regime: wetting film. - In the film, $\left|\frac{\mathrm{d} e}{\mathrm{~d} h}\right|$ is small and minimization of (5) gives

$$
\pi(e)=\frac{\gamma}{b}+\rho g h
$$

and we get for the profile $e(h)$ :

$$
e(h)=\left(\frac{K^{-2} a^{2}}{h+\frac{K^{-2}}{b}}\right)^{1 / 3}
$$

with $K^{-2}=\gamma / \rho g$.

This wetting film joins the macroscopic meniscus with an angle $\theta=\frac{2}{3}\left(\frac{e_{\mathrm{c}}}{b}\right)^{1 / 2}$ and ends up for $e=e_{0}=a\left(\frac{3 \gamma}{2 S}\right)^{1 / 2}$ at height $\bar{H}$ given by :

$$
\bar{H}=K^{-2}\left(\frac{1}{e_{0}}-\frac{1}{b}\right) .
$$

\section{Dynamics.}

A detailed analysis of the dynamics of spreading films will be presented in a forthcoming paper [4]. We will consider here only the case of $S>S_{\mathrm{c}}$. Moreover, the description of the rise of the macroscopic meniscus (Eqs . $(6,7)$ ) will not be set out in this paper because currently our experiments do not focus on this regime. Let us just mention that the speed of creeping of the meniscus is governed by the well-known Tanner's law [6]: $\theta^{3} \sim U / v^{*}$ with $v^{*}=\gamma / \eta$ ( $\eta$ being the viscosity of the liquid) and $\theta$ the dynamic contact angle that verifies equation (7) (we assume that pressures equilibrate quickly); this meniscus is established in a very short time $\left(\tau=\frac{b}{2 v^{*}}\left(\frac{a}{b}\right)^{-2 / 3}\right)$. An adiabatic film (precursor-film [7]) is pushed up by the meniscus until the latter reaches equilibrium.

Let us write the two basic equations determining the creeping of the microscopic film :

(i) assuming that the film creeps with a Poiseuille flow, the hydrodynamic equation can be written:

$$
3 \eta \frac{U}{e^{2}}=-\frac{\partial P}{\partial h}
$$

$U$ is the mean velocity of the liquid front and $P$ is the pressure inside the film :

$$
\begin{aligned}
& P=\gamma /(b+e)-\pi(e) \\
& \text { for an horizontal fiber } \\
& P=\gamma /(b+e)-\pi(e)+\rho g h \\
& \text { for a vertical one } ;
\end{aligned}
$$

(ii) the mass conservation equation is :

$$
\frac{\mathrm{d}}{\mathrm{d} h}(e U)+\frac{\partial e}{\partial t}=0 .
$$

By combining (10) and (11), we obtain for a vertical fiber :

$$
-\frac{\rho g}{\eta} e^{2} \frac{\partial e}{\partial h}-\frac{\partial}{\partial h}\left(\frac{v^{*} a^{2}}{e} \frac{\partial e}{\partial h}\right)+\frac{\partial e}{\partial t}=0 .
$$

Following [8], we look for a self-similar solution for the profile $e(h, t): e(h, t)=z_{\ell}(t) f\left(h / h_{\ell}(t)\right)$. By substituting this expression in (12), we get :

$$
\begin{aligned}
& z_{\ell}(t)=\left(v^{*} t\right)^{-1 / 5} K^{-4 / 5} a^{2 / 5} \\
& h_{\ell}(t)=\left(v^{*} t\right)^{3 / 5} K^{2 / 5} a^{4 / 5}
\end{aligned}
$$

and :

$$
\frac{\mathrm{d} f}{\mathrm{~d} u}\left(f^{2}+\frac{3}{5} u\right)+\frac{\mathrm{d}}{\mathrm{d} u}\left(\frac{1}{f} \frac{\mathrm{d} f}{\mathrm{~d} u}\right)+\frac{f}{5}=0
$$


where $u=h / h_{\ell}(t)$. Two regimes can be distinguished according to the value of $u$ :

$u<1$ (small heights). The static film is already established and viscous terms have to be neglected. Then equation (13) becomes :

$$
f^{2} \frac{\mathrm{d} f}{\mathrm{~d} u}+\frac{\mathrm{d}}{\mathrm{d} u}\left(\frac{1}{f} \frac{\mathrm{d} f}{\mathrm{~d} u}\right)=0
$$

The solution of (14) is $f(u)=\left(u+u_{0}\right)^{-1 / 3}$ with $u_{0}=K^{-2} / b . h_{\ell}(t)$. We thus get back the static profile (8).

$u>1 . e(h, t)<e_{\mathrm{c}}$ and the disjoining pressure now is larger than the hydrostatic pressure. Equation (13) becomes :

$$
\frac{3}{5} u \frac{\mathrm{d} f}{\mathrm{~d} u}+\frac{f}{5}+\frac{\mathrm{d}}{\mathrm{d} u}\left(\frac{1}{f} \frac{\mathrm{d} f}{\mathrm{~d} u}\right)=0 .
$$

The solution of $(15)$ is $f(u)=2 / u^{2}$ that we can rewrite :

$$
e(h, t)=\frac{2 v^{*} a^{2}}{h^{2}} t
$$

The tip height $h_{\mathrm{d}}$ of this dynamic tongue is given by

$$
h_{\mathrm{d}}^{2}=D\left(e_{0}\right) \cdot t
$$

with $D\left(e_{0}\right)=2 v * a^{2} / e_{0}$.

For $v^{*}=2500 \mathrm{~cm} / \mathrm{s}, \quad a=3 \AA$ and $e_{0}=30 \AA$, $D\left(e_{0}\right)=10^{-5} \mathrm{~cm} / \mathrm{s}:$ one centimeter of fiber is wetted in one day.

The static profile ends up at height $h_{\mathrm{s}}$ determined by matching the solutions of equations (14) and (15) $: \frac{2}{u^{2}}=\left(u+u_{0}\right)^{-1 / 3}$ and $u \sim 1$.

Let us call $t_{3}$ the time defined by $u_{0}=1$.

$$
t_{3}=\frac{1}{v^{*}} K^{-4} a^{-4 / 3} b^{-5 / 3} .
$$

This time defines the moment when gravity acts. For $v^{*}=2500 \mathrm{~cm} / \mathrm{s}, K^{-1}=1 \mathrm{~mm}, a=3 \AA$ and $b=$ $30 \mu \mathrm{m}, t_{3}=1$ year.

As $u_{0}<1\left(t<t_{3}\right), h_{\mathrm{s}}$ is given by :

$$
h_{\mathrm{s}}^{2}=D\left(e_{\mathrm{c}}\right) t
$$

with $D\left(e_{\mathrm{c}}\right)=2 v^{*} a^{2} / e_{\mathrm{c}}$.

As $u_{0}>1\left(t>t_{3}\right)$, the diffusion law (19) changes to :

$$
h_{\mathrm{s}}=K^{2 / 5} a^{4 / 5}(v * t)^{3 / 5} .
$$

The creep rises faster, and the final height $\bar{H}$ (Eq. (9)) is reached for $h_{\mathrm{s}}=h_{\mathrm{d}}=\bar{H}$ at time $t_{4}$ :

$$
t_{4} \sim \frac{K^{-4}}{v^{*}} \frac{a^{2}}{e_{0}^{5}} .
$$

For typical values of the parameters (see above), one might as well say never since $t_{4}=200$ years. These profiles are drawn in figure $2 b$.

\section{Experiments.}

4.1 PROOFS FOR THE EXISTENCE OF A WETTING FILM. - We have first looked for the existence of the above described wetting film. Figure 3. is a microphotography of two polyester fibers (of diameter 20 micrometers). We have spreaded on one of the fibers a silicone oil, in which a fluorescent dye (NBD) had been introduced up to saturation and we have looked at the fibers using a UV light source. We can see on the picture that there is some fluorescence between the unspreaded droplets, thus revealing a liquid film. The second fiber on the picture is dry and is shown as a reference. This simple experiment proves that in spite of the presence of unspreaded drops, the fiber is actually wetted.

We have also noticed that when a small drop is close to a large one, the former empties in the latter ; this phenomenon in analogous to the one of two unequal soap bubbles connected by a straw. From the study of the dynamics of this process, we were able [9] to calculate an estimated wetting film thickness for a 19 micrometers Nylon fiber covered by a spin finish oil ; this thickness of order $200 \AA$ is in qualitative agreement with our theoretical predictions, although involving too large Hamaker constants.

4.2 CREEPING OF A LIQUID ON A FIBER: FIRST OBSERVATIONS.

4.2.1 Experimentals. - We have studied the upward creep of liquid $\alpha$-methyl naphtalene :

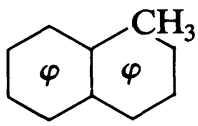

$\left(\gamma_{\text {lab }}=36 \mathrm{dyn} / \mathrm{cm}\right.$ and $\eta=1.5 \times 10^{-2} \mathrm{P}, \quad v^{*}=$ $\gamma / \eta=2400 \mathrm{~cm} / \mathrm{s}$ ) on polypropylene fibers of diameter $45 \mu$. We have investigated the profile of the creeping liquid by an analysis of the electron spin resonance signal $\Sigma(h, t)$ of a nitroxide label of formula<smiles>CC1(C)CCCC(C)(C)N1O</smiles>

dissolved in the $\alpha$-methyl naphtalene at a concentration of $4.7 \mathrm{M}$. The experimental set-up is shown in figure 4. By using this method, we benefit from the very high sensitivity of ESR (it should be possible to detect a wetting film of $20 \AA$ on a single fiber). We have checked that the Young contact angle fibers is zero by observation through microscope ; nevertheless, there are some parts of the fibers showing a contact angle slightly above zero, 


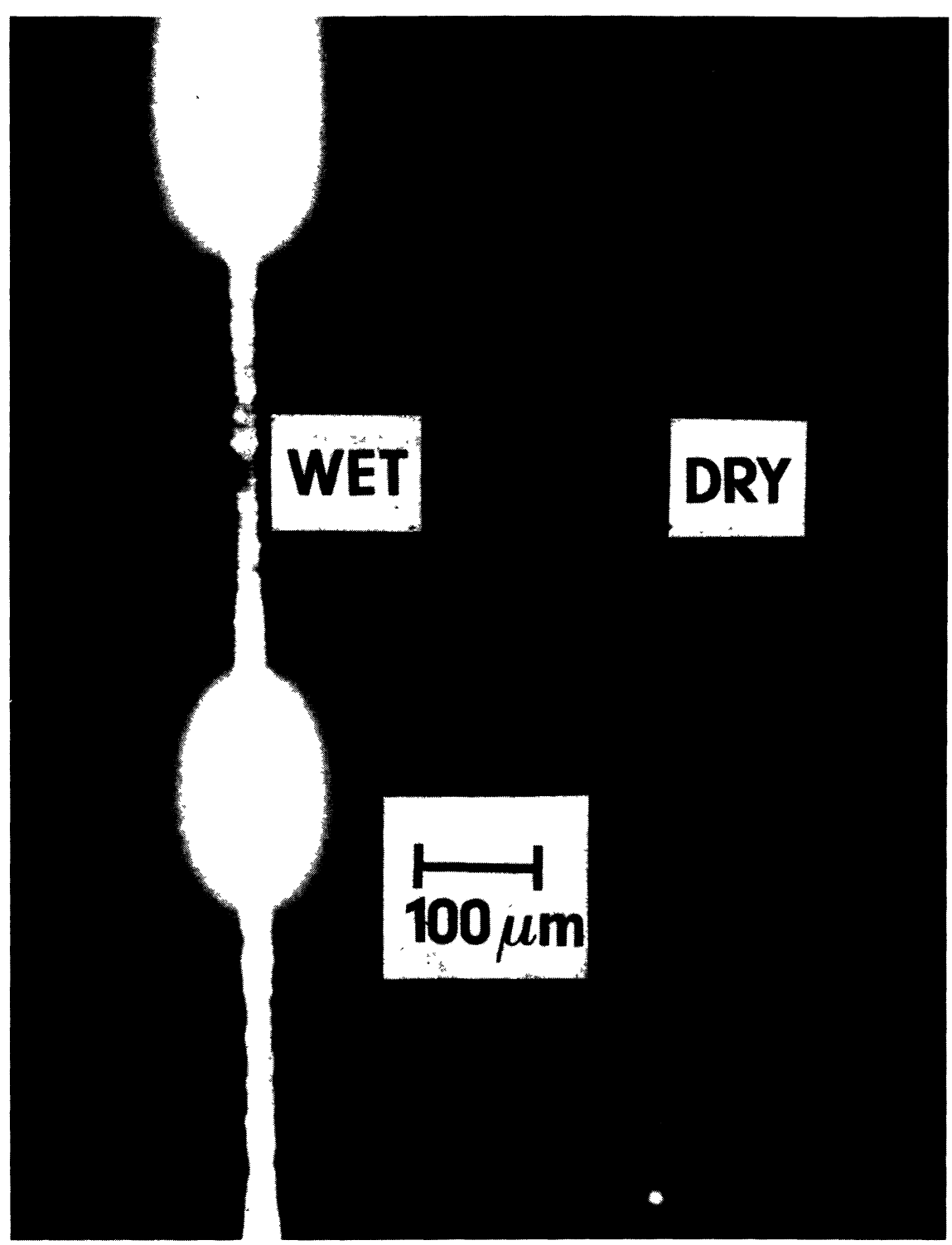

Fig. 3. - Photography under microscope of two polyester fibers (diameter $=20$ microns). One fiber has been covered by fluorescent dyed silicone (see text for explanation).

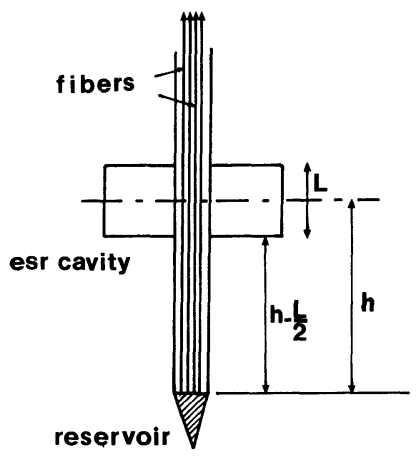

Fig. 4. - Schematical representation of the experimental set-up used for the profile determination. $h$ is the height above the reservoir and $L$ the size of the cavity $(L=2.3 \mathrm{~cm})$. revealing that the surface is not chemically homogeneous. Seven fibers are set in the same glass test tube in order to increase the signal/noise ratio (the noise comes mostly of the electronic part of the spectrometer). We call $e(h, t)$ the thickness of the film as a function of the height $h$ above the reservoir and the time $t$. The ESR signal $\Sigma(h, t)$ rigorously is the convolution of $e(h, t)$ with the apparatus function depending on the cavity size (height $L$, $L=23 \mathrm{~mm}$ ) and on the gain of the amplifier. The ESR spectrum of the reservoir solution is reduced to a single peak because of the high label concentration leading to spin exchange. On the other hand the spectrum of the labelled liquid on the fiber consists of three peaks : we think that it is due to a slower diffusion of labels molecules leading to less exchange [10] and slower rotational diffusion because of label 
adsorption on the fiber or a possible diffusion of the label inside the fiber. This problem is still open. In a first approximation, the thickness $e$ of the film can be deduced from $\Sigma(h, t)$ by a simple calibration where $\Sigma(h, t)$ is the height of the central peak: $e=127 \Sigma, e$ in $\AA$ and $\Sigma$ in ESR-signal units.

4.2.2 Velocity of the upward creep. - The labelled liquid is introduced into the bottom of the vessel at $t=0$. We try to detect the onset of the signal at different heights above the reservoir : because of the small value of the signal/noise ratio, we have to record several ESR spectra and average them. Each spectrum is rather long to record $(10 \mathrm{~min})$ since we use the highest sensitivity of the ESR apparatus involving large time-constants. That is why we got only two data points : $h_{1}-L / 2=261 \mathrm{~mm}, t_{1}=$ $52 \mathrm{~min} ; h_{2}-L / 2=516 \mathrm{~mm}, t_{2}=160 \mathrm{~min}$. If we assume that the dependence on $t$ for the advance of this tongue (corresponding to a film of $20 \AA$ ) is a power law : $h-L / 2 \sim t^{\alpha}$ we get $\alpha=0.60 \pm 0.05$. We remain very careful as regards that result because of the little data, but we have been quite surprised not to have got a diffusion law $(\alpha=0.5)$ : both capillary rise and creeping of a microscopic dynamic film (Eq. (17)) lead to such a law. Another feature is that experimental upward creeping times are much too small to be interpreted as a wetting phenomenon. The diffusion law which ruled the advance of the dynamic tongue has been proposed above (Eq. (17)) :

with $\quad D\left(e_{0}\right)=2 v * a^{2} / e_{0}$.

The diffusion coefficient $D\left(e_{0}\right)$ associated with our system can be theoretically estimated: $D\left(e_{0}\right)=$
$10^{-5} \mathrm{~cm} / \mathrm{s}$ (one centimeter of fiber is wetted in one day). That is why we suspected a capillary phenomenon : electron microscope pictures which have been recently taken in the research center of Atochem in Levallois (we thank for their kindness C. Taupin and M. Allain) show that the surface of our polypropylene fibers is actually rough (Fig. 5). Axisymmetric grooves may be observed and it is reasonable to assume that the liquid has been conveyed through a capillary process.

Lucas-Washburn's equation [11,12] describes the simple situation of a capillary tube (radius $r$ ) partially dipped in an infinite reservoir ; assuming a Poiseuille flow it reads as

$$
\frac{\mathrm{d} h}{\mathrm{~d} t}=\frac{r^{2}}{3 \eta} \frac{\partial}{\partial h}\left(\frac{\gamma}{r}\right) \quad h \ll K^{-2} / r .
$$

That can be roughly integrated :

$$
h^{2}=D(r) \cdot t \text { with } D(r)=\frac{2}{3} v^{*} \cdot r .
$$

From our experimental data $\left(h=h_{1}, t=t_{1}\right.$, $v^{*}=2400 \mathrm{~cm} / \mathrm{s}$ ) we get $r=1$ micrometer. This is in a quite good agreement with what could be observed on the microscope pictures, even if the grooves seem to be a little smaller than this value of one micrometer. Maybe we have an unusual capillary rise as observed by Moldover and Gammon [13] : when the capillary tube has a diameter of the order of the range of intermolecular forces, the macroscopic capillary rise is modified : the liquid creeps higher than $K^{-2} / r$. Legait and De Gennes [14] have analysed such a situation between two vertical plates distant from $r$. Because of the disjoining pressure in this confined space, they propose to replace $r$ by $r^{*}=r-1.5 a^{2 / 3} r^{1 / 3}$ so that the liquid rises up to

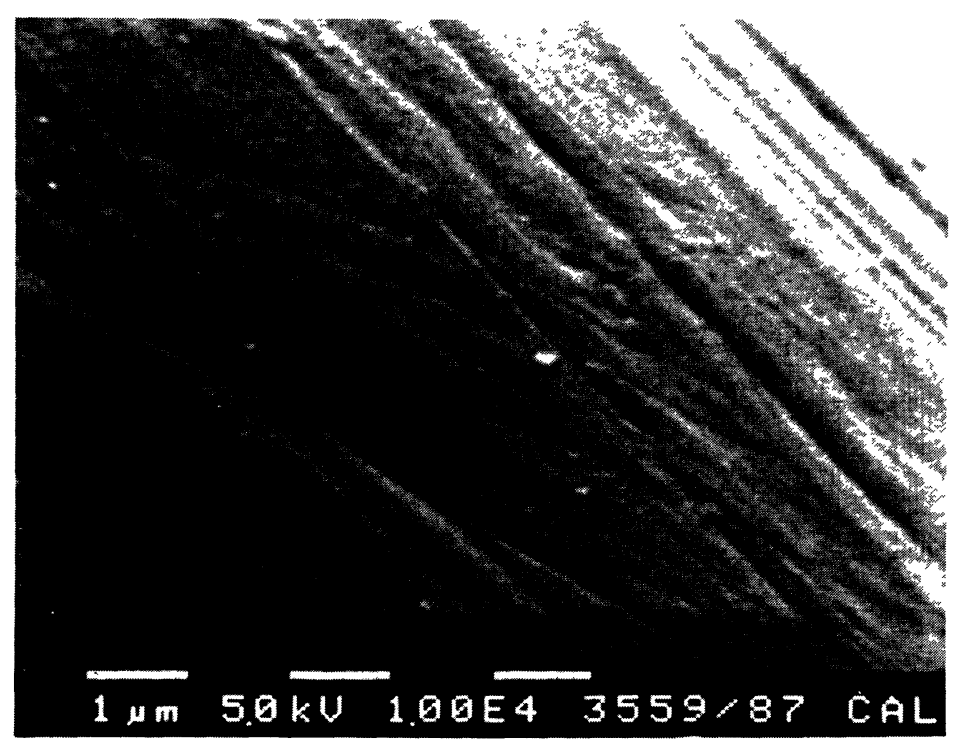

Fig. 5. - Electron microscope photography of the surface of a polypropylene fiber : axial striations can be observed. 
$K^{-2} / r^{*}$. In the Lucas-Washburn equation, the gradient term is altered (we have to replace $r$ by $\left.r^{*}\right)$ while the hydrodynamic radius remains unchanged. The creeping still is diffusive, but the coefficient of diffusion is now :

$$
D\left(r, r^{*}\right)=\frac{2}{3} \cdot v^{*} \cdot \frac{r^{2}}{r^{*}}
$$

For a given $r$, the rise time is reduced. Of course this correction on $r$ is very small for $r \sim 1$ micrometer $\left(\frac{\Delta r}{r} \sim 1 \%\right)$; but it could be very interesting to study anomalous capillary rise by working on fibers with very small grooves $(r<1000 \AA)$. We currently work on this problem which is an original expression of long-range interactions.

4.2.3 Profiles. - Let us recall that for non-adsorbed spin labels the thickness of the film $e(h, t)$ is proportionnal to the ESR-signal: $e(h, t)=$ $127 \Sigma(h, t)$; we present for our data either $\Sigma$ or $e:$ in a regime where adsorption is suspected to be predominant $e$ does not mean anything more.

Our results are drawn in figures 6 to $9: e$ versus $t$ for $h$ constant in figure $6, \Sigma$ versus $h$ for $t$ constant in figure $7, \log \Sigma$ versus $\log \left(h+h_{0}\right)$, in figure 8 $\left(h_{0}=K^{-2} / b\right)$. The first remark is that two regimes, more and more distinguishable as time goes by, can be seen in figures 7 or 8 . We call $h_{\mathrm{K}}$ the height of the kink between the two regimes.

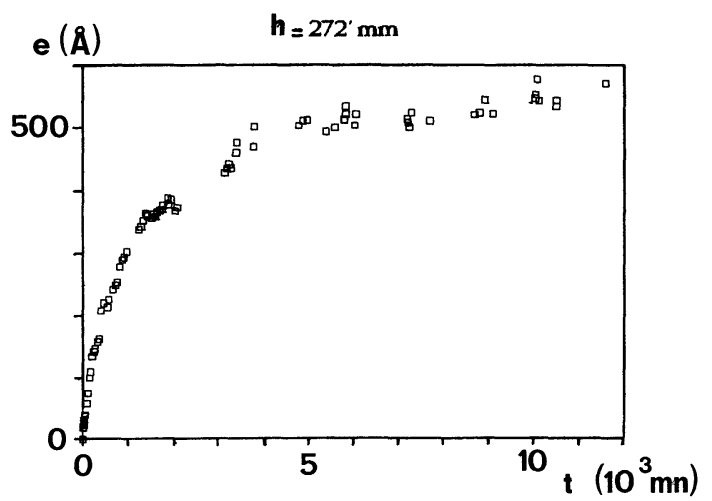

Fig. 6. - Thickness $e$ of the liquid film versus time for $h=272 \mathrm{~mm}$.

For $h<h_{\mathrm{K}}$ the intensity of the signal $\Sigma$ is much too large to be relevant of wetting or capillarity and may be due to the strong adsorption of the labelled molecules onto the bottom of the fiber. We cannot explain the strange behavior: $\Sigma(h) \sim\left(h+h_{0}\right)^{-\alpha}$ with $\alpha=6.0 \pm 0.2$.

A very striking feature is that $h_{\mathrm{K}}$ is equal to $h_{0}\left(h_{0}=K^{-2} / b\right)$, the error bar for this measure being $1 \mathrm{~cm}$, half-length on the ESR cavity. This may be a curious coincidence, and we are working on this problem by using fibers of different diameters.

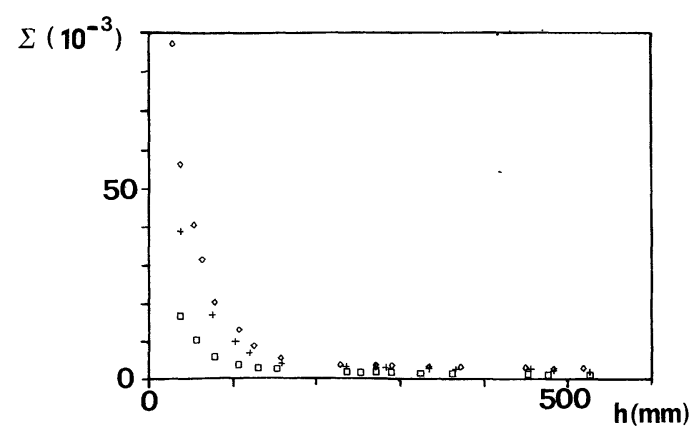

Fig. 7. - ESR signal $\Sigma$ versus height $h$ above the reservoir for : $\square(t=375 \mathrm{~min}) ;+(t=1437 \mathrm{~min}) ; \diamond(t=$ $3308 \mathrm{~min}$.)

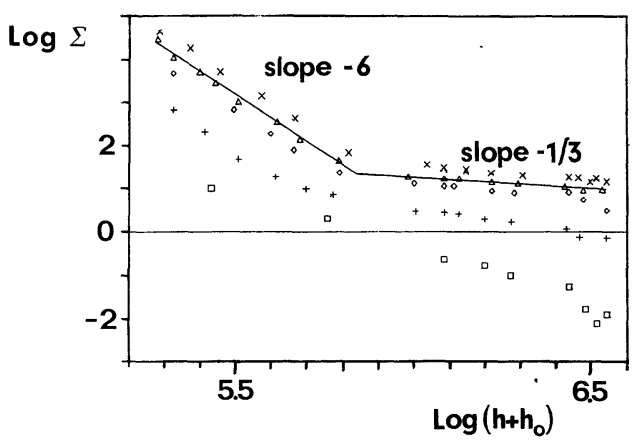

Fig. 8. $-\log \Sigma$ versus $\log \left(h+h_{0}\right)$ with $h_{0}=K^{-2} / b: \square$ $(t=117 \mathrm{~min}) ; \quad+(t=375 \mathrm{~min}) ; \diamond(t=1437 \mathrm{~min}) ;$ $\Delta(t=3308 \mathrm{~min}) ; \times(t=10049 \mathrm{~min})$.
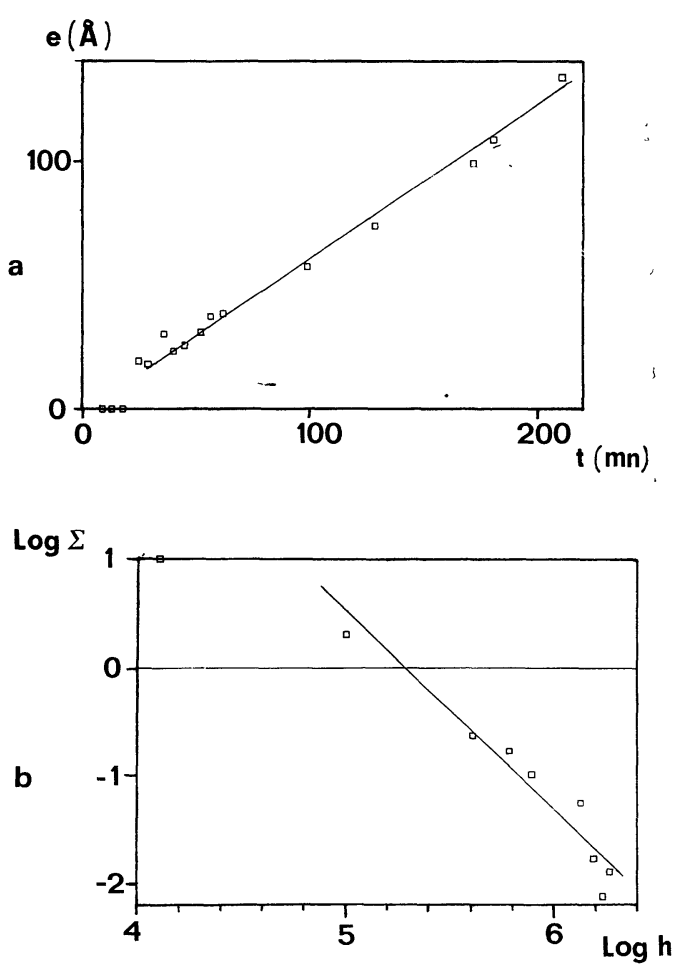

Fig. 9. - Short time behavior: (a) $e(t)$ with $t$ around $117 \mathrm{~min} ; h-L / 2=272 \mathrm{~mm}$; (b) logarithmic profile of the film at $t=117 \mathrm{~min}$. 
For $h>h_{\mathrm{K}}$ we first get profiles verifying: $e \sim t$ and $e \sim h^{-\alpha}$ with $\alpha=2.1 \pm 0.6$ (Fig. 9). That could be compatible with the creeping of a dynamic tongue (Eq. (16)) but this rise is too rapid to be interpreted as a wetting phenomenon (Sect. 4.2.2). Then (Fig. 8) $\alpha$ decreases down to the value $\alpha=$ $0.30 \pm 0.10$. This exponent is compatible with the asymptotic value 0.33 of equation (8) (static profile of a microscopic film on a vertical fiber) : that is why we interprete this film as a wetting film. Because of the grooves, liquid is first carried up by capillarity ; then each groove acts as a reservoir from which a wetting film can be laterally emitted. This process is quasi-instantaneously: time to diffuse on length $b$ (Eq. (19)) is for our system about five seconds. One can roughly estimate the contribution of the grooves to the ESR signal, substract it from $\Sigma$, and using equation (8) we get from the measured profile $a=2.5 \AA$ or a reasonable effective Hamaker constant $A=A_{\mathrm{SL}}-A_{\mathrm{LL}}=4.1 \times 10^{-13}$ ergs.

\section{Conclusion.}

We have shown that thin textile fibers can be covered by a liquid film when they are in contact with a reservoir containing a wetting liquid. Compared with the theory (Sect. 2), the dynamics of the creeping is too rapid: this express-rise can be explained by the surface roughness, and it can be industrially interesting to provoke the existence of such axial grooves. A microscopic wetting film can then develop from these striations, the measured profile $e(h)$ obeys power law in agreement with the theoretical prediction. Systematic experiments with fibers of different diameters and polarities are currently under progress.

\section{Acknowledgment.}

One of us (D.Q.) thanks ATOCHEM for financial support.

\section{References}

[1] Chou, T. W., McCullough, R. and Pipes, B., in Pour la Science, French issue of Sci. Am. (Décembre 1986).

[2] De Gennes, P. G., Rev. Mod. Phys. 57 (1985) 827.

[3] Brochard-Wyart, F., J. Chem. Phys. 84 (1986) 4664.

[4] Brochard-Wyart, F., Di Meglio, J. M. and QUERE, D., submitted to Langmuir.

[5] Carroll, B. J., J. Colloid Interface Sci. 57 (1976) 488.

[6] Tanner, L., J. Phys. D 12 (1979) 1473.

[7] De Gennes, P. G., C. R. Hebd. Séan. Acad. Sci. Paris Sér. II 298 (1986) 111.
[8] Joanny, J. F., Thesis, Paris (1985).

[9] Di Meglio, J. M., C. R. Hebd. Séan. Acad. Sci. Paris Sér. II, 303 (1986) 437.

[10] Sackman, E. and Trauble, H., J.A.C.S. 94 (1972) 4482.

[11] LuCAS, R., Kolloid Z., 23 (1918) 15.

[12] Washburn, E. W., Phys. Rev. 17 (1921) 273.

[13] Moldover, M. R. and Gammon, R. W., J. Chem. Phys. 80 (1984) 528.

[14] Legait, B. and De Gennes, P. G., J. Phys. Lett. 45 (1984) 647. 